\title{
Severe COVID-19 disease and thromboinflammation
}

\section{Enfermedad Grave COVID-19 y tromboinflamación}

\author{
Carlos Jerjes-Sánchez ${ }^{1,2 *}$
}

${ }^{1}$ Dirección de Investigación Clínica, Instituto de Cardiología y Medicina Vascular, TecSalud, México; ${ }^{2}$ Presidencia del Comité de Investigación y Dirección del Programa Académico de Cardiología de Posgrado, Escuela de Medicina y Ciencias de la Salud, Tecnológico de Monterrey, Monterrey, México

As of May 29, 2020, the coronavirus disease (COVID)-19 pandemic involved 6 million reported cases and had claimed 2,530,000 lives with mortality of $367,000^{1}$. The disease is spreading in almost every country, causing widespread health challenges and social instability ${ }^{1}$. The World Health Organization (WHO) named it COVID19 disease and alerted countries with vulnerable health systems to establish an urgent response $^{2}$. People most susceptible to COVID-19 include those with underlying health conditions ${ }^{1}$. COVID-19 is a rapidly emerging worldwide situation in which clinical observations and multidisciplinary efforts are necessary to establish a fundamental basis for improving patient care, especially for this heterogeneous population.

Among common complications observed in deceased patients with COVID-19 (acute respiratory distress syndrome, sepsis, acute cardiac injury, heart failure, acute kidney injury, and hypoxic encephalopathy), venous thromboembolism emerges as a severe and frequent complication, foreshadowing a poor clinical outcome. The main risk factor of cardiovascular disease is endothelial dysfunction and a chronic inflammatory state. Most patients with severe COVID-19 disease have aging, hypertension, diabetes, former smoking, and comorbid obesity. In addition, ischemic heart disease, heart failure, cerebrovascular disease, chronic lung disease, as well as chronic kidney diseases are frequent comorbidities ${ }^{3}$. Both clinical conditions are an excellent model for thromboinflammation and complications related.

Severe acute respiratory syndrome coronavirus 2 (SARS-CoV-2) infection leads to a cytokine storm, inducing endothelial activation, cell damage, increased platelet aggregation, and thrombi sensitivity. Furthermore, recruitment and activation of leukocytes at the vascular wall leading to arterial inflammation within coronary plaques induce a disruption in vulnerable plaques $^{4,5}$. Interleukin-6 (IL-6) induces the expression of several prothrombotic factors, including intravascular tissue factor, VIII factor, von Willebrand factor, fibrinogen, and plasminogen activator inhibitor type 1. Moreover, IL-6 causes dysregulation of antithrombin III, protein $\mathrm{S}$, and thrombomodulin ${ }^{5,6}$.

Furthermore, SARS-CoV-2 could activate immunothrombosis, another thrombosis mechanism that includes the innate immune system, the neutrophil extracellular genetic traps, and the immunothrombosis dysregulation ${ }^{6}$. All these mechanisms can induce diffuse microangiopathy with micro- and macro-thrombosis? In addition, antiphospholipid antibodies that abnormally target phospholipid proteins can arise transiently in patients with critical illness and infections, including COVID-198,9. Further, severe SARS-CoV-2 disease may predispose the patient
Available online: 14-09-2020 Arch Cardiol Mex (Eng). 2020;90(3):257-258 www.archivoscardiologia.com license (http://creativecommons.org/licenses/by-nc-nd/4.0/). 
to both venous and arterial thrombosis as it causes severe acute hypoxia, immobilization, and diffuse intravascular coagulation ${ }^{10}$. In patients with venous thromboembolism, it is possible to identify at the beginning endothelial colony-forming cells (a subpopulation of circulating endothelial progenitor cells), and increased tumor necrosis factor- $\alpha$ synthesis that may resemble the cytokine storm identified in patients with COVID-192. Although preliminary evidence suggests anticoagulation benefit mortality in severe COVID-19 disease ${ }^{11}$, including anti-inflammatory mechanisms, current and robust confirmation is mandatory to identify the best primary and secondary prevention strategy, as well as the optimal therapeutic approach, including thrombolytic regimens.

\section{References}

1. Meagher KM, Cummins NW, Bharucha AE, Badley AD, Chlan LL, Wright RS. COVID-19 ethics and research. Mayo Clin Proc. 2020;95:1119-23.
2. Alvarado-Moreno JA, Majluf-Cruz A. COVID-19 and dysfunctional endothelium: the Mexican scenario. Arch Med Res. 2020;2020:1016.

3. Chen T, Wu D, Chen H, Yan W, Yang D, Chen G, et al. Clinical characteristics of 113 deceased patients with coronavirus disease 2019: retrospective study. BMJ. 2020;2020:368.

4. Musher DM, Abers MS, Corrales-Medina VF. Acute infection and myocardial infarction. N Engl J Med. 2019;380:171-6.

5. Atri D, Siddiqi HK, Lang J, Nauffal V, Morrow DA, Bohula EA. COVID-19 for the cardiologist: a current review of the virology, clinical epidemiology, cardiac and other clinical manifestations and potential therapeutic strategies. JACC. 2020;5:1016.

6. Vazquez-Garza E, Jerjes-Sanchez C, Navarrete A, Joya-Harrison J, Rodriguez D. Venous thromboembolism: thrombosis, inflammation, and immunothrombosis for clinicians. J Thromb Thrombolysis. 2017; 44:377-85.

7. Liu PP, Blet A, Smyth D, Li H. The science underlying COVID-19: implications for the cardiovascular system. Circulation. 2020;2020:47549.

8. Zhang Y, Xiao M, Zhang S, Xia P, Cao W, Jiang W, et al. Coagulopathy and antiphospholipid antibodies in patients with Covid-19. N Engl J Med. 2020;382:e38.

9. Bowles L, Platton S, Yartey N, Dave M, Lee K, Hart DP, et al. Lupus anticoagulant and abnormal coagulation tests in patients with Covid-19. N Engl J Med. 2020;2020:NEJMc2013656.

10. Klok FA, Kruip MJ, van der Meer NJ, Arbous MS, Gommers DA, Kant KM et al. Incidence of thrombotic complications in critically ill ICU patients with COVID-19. Thromb Res. 2020;191:145-7.

11. Tang $\mathrm{N}$, Bai $\mathrm{H}$, Chen $\mathrm{X}$, Gong J, Li D, Sun Z. Anticoagulant treatment is associated with decreased mortality in severe coronavirus disease 2019 patients with coagulopathy. J Thromb Haemost. 2020;18:1094-9. 